\title{
Phenytoin Reduces Activity of Cardiac Ryanodine Receptor 2; A Potential Mechanism for Its Cardioprotective Action $\$$
}

\author{
A. Ashna, D.F. van Helden, C. dos Remedios, P. Molenaar, and D.R. Laver
}

School of Biomedical Sciences and Pharmacy, University of Newcastle and Hunter Medical Research Institute, Callaghan, New South Wales, Australia (A.A., D.F.v.H., D.R.L.); Bosch Institute, Discipline of Anatomy, University of Sydney, Sydney, New South Wales, Australia (C.d.R.); School of Biomedical Sciences, Queensland University of Technology, Brisbane, Queensland, Australia (P.M.); and Northside Clinical School of Medicine, University of Queensland, Cardio-vascular Molecular \& Therapeutics Translational Research Group, The Prince Charles Hospital, Chermside, Queensland, Australia (P.M.)

Received July 12, 2019; accepted January 16, 2020

\section{ABSTRACT}

Phenytoin is a hydantoin derivative that is used clinically for the treatment of epilepsy and has been reported to have antiarrhythmic actions on the heart. In a failing heart, the elevated diastolic $\mathrm{Ca}^{2+}$ leak from the sarcoplasmic reticulum can be normalized by the cardiac ryanodine receptor 2 (RyR2) inhibitor, dantrolene, without inhibiting $\mathrm{Ca}^{2+}$ release during systole or affecting $\mathrm{Ca}^{2+}$ release in normal healthy hearts. Unfortunately, dantrolene is hepatotoxic and unsuitable for chronic long-term administration. Because phenytoin and dantrolene belong to the hydantoin class of compounds, we test the hypothesis that dantrolene and phenytoin have similar inhibitory effects on RyR2 using a single-channel recording of RyR2 activity in artificial lipid bilayers. Phenytoin produced a reversible inhibition of RyR2 channels from sheep and human failing hearts. It followed a hyperbolic dose response with maximal inhibition of $\sim 50 \%$, Hill coefficient $\sim 1$, and $\mathrm{IC}_{50}$ ranging from 10 to $20 \mu \mathrm{M}$. It caused inhibition at diastolic cytoplasmic $\left[\mathrm{Ca}^{2+}\right]$ but not at $\mathrm{Ca}^{2+}$ levels in the dyadic cleft during systole. Notably, phenytoin inhibits RyR2 from failing human heart but not from healthy heart, indicating that phenytoin may selectively target defective RyR2 channels in humans. We conclude that phenytoin could effectively inhibit RyR2-mediated release of $\mathrm{Ca}^{2+}$ in a manner paralleling that of dantrolene. Moreover, the $\mathrm{IC}_{50}$ of phenytoin in RyR2 is at least threefold lower than for other ion channels and clinically used serum levels, pointing to phenytoin as a more human-safe alternative to dantrolene for therapies against heart failure and cardiac arrythmias.

\section{SIGNIFICANCE STATEMENT}

We show that phenytoin, a Na channel blocker used clinically for treatment of epilepsy, is a diastolic inhibitor of cardiac calcium release channels [cardiac ryanodine receptor 2 (RyR2)] at doses threefold lower than its current therapeutic levels. Phenytoin inhibits RyR2 from failing human heart and not from healthy heart, indicating that phenytoin may selectively target defective RyR2 channels in humans and pointing to phenytoin as a more human-safe alternative to dantrolene for therapies against heart failure and cardiac arrhythmias.

\section{Introduction}

Proper cardiac contraction and rhythm relies on the balance of $\mathrm{Ca}^{2+}$ fluxes across the sarcoplasmic reticulum (SR) and sarcolemma of myocytes (Bers, 2006; Eisner et al., 2017). During an action potential, $\mathrm{Ca}^{2+}$ influx into the cell via L-type $\mathrm{Ca}^{2+}$ channels activates RyR2 and the release of $\mathrm{Ca}^{2+}$ from the $\mathrm{SR}$ by a process called $\mathrm{Ca}^{2+}$-induced $\mathrm{Ca}^{2+}$ release (Fabiato, 1983). The combination of $\mathrm{Ca}^{2+}$ influx and $\mathrm{SR}$ release increases the bulk cytoplasmic $\mathrm{Ca}^{2+}$ concentration $\left[\mathrm{Ca}^{2+}\right]_{\mathrm{c}}$ to $\sim 1 \mu \mathrm{M}$ (Shannon et al., 2003). During $\mathrm{Ca}^{2+}$ release, the concentration of free $\left[\mathrm{Ca}^{2+}\right]$ in the SR decreases from $\sim 1 \mathrm{mM}$ to between 0.4 and $0.7 \mathrm{mM}$ (Zima et al., 2008). Modeling studies predict that during $\mathrm{Ca}^{2+}$ release, $\left[\mathrm{Ca}^{2+}\right]$ in the $14 \mathrm{~nm}$ cleft between the $\mathrm{SR}$

This work was funded by NSW Health Infrastructure Grant through the Hunter Medical Research Institute and the National Health and Medical Research Council Project Grant [APP1082204].

https://doi.org/10.1124/mol.119.117721.

S This article has supplemental material available at molpharm. aspetjournals.org. and sarcolemma reaches $\sim 100 \mu \mathrm{M}$ (Laver et al., 2013). With membrane repolarization, $\mathrm{Ca}^{2+}$-induced $\mathrm{Ca}^{2+}$ release ceases, RyR2 channels close, and $\mathrm{SR} \mathrm{Ca}^{2+}$ release terminates. In addition, removal of excess cytoplasmic $\mathrm{Ca}^{2+}$ by the $\mathrm{Na}^{+}-\mathrm{Ca}^{2+}$ exchanger in the sarcolemma tends to depolarize the membrane (Bers, 2002, 2006; Dibb et al., 2007). Thus, excess SR Ca ${ }^{2+}$ release through "leaky" RyR2 during diastole can lead to both a reduced diastolic SR $\mathrm{Ca}^{2+}$ load, systolic $\mathrm{Ca}^{2+}$ release, and muscle contraction as seen in heart failure (Yano et al., 2005; Oo et al., 2015) as well as increased sarcoplasmic depolarization, excitability, and cardiac arrhythmias (George et al., 2006, 2007).

Some agents that partially inhibit RyR2 activity reduce diastolic $\mathrm{Ca}^{2+}$ leak and protect against inherited adrenergicinduced arrhythmias (flecainide, carvedilol) (Hilliard et al., 2010; Hwang et al., 2011; Pölönen et al., 2018) and arrhythmias in acquired disorders such as heart failure (e.g., dantrolene) (Yano et al., 2005). Dantrolene is a hydantoin derivative that was first used as a skeletal muscle relaxant and is now prescribed for acute treatment of malignant hyperthermia

ABBREVIATIONS: CaM, calmodulin; ICM, ischemic cardiomyopathy; $P_{0}$, open probability; RyR2, cardiac ryanodine receptor; SR, sarcoplasmic reticulum. 
(Muehlschlegel and Sims, 2009). In failing heart, dantrolene selectively reduces diastolic $\mathrm{Ca}^{2+}$ leak without inhibiting $\mathrm{Ca}^{2+}$ release during systole and without otherwise affecting the function of normal healthy hearts (Maxwell et al., 2012; Chou et al., 2014). These properties favor a therapeutic role for dantrolene, but unfortunately, dantrolene is hepatotoxic with chronic long-term administration (Paul-Pletzer et al., 2002) and is therefore not suitable as a chronic heart failure therapy. Here, we explore the possibility that other less-toxic hydantoin derivatives produce similar inhibitory actions on RyR2.

Phenytoin (Dilantin) is a hydantoin derivative that is used clinically for the treatment of epilepsy (Twombly et al., 1988) and has been shown to offer protection against cardiac arrythmias (Conn, 1965; Conn et al., 1967; Rosen et al., 1967; Eddy and Singh, 1969). Phenytoin affects several cellular processes, including protein phosphorylation and neurotransmitter release in brain (Pincus and Lee, 1973; Lang et al., 1993). Its antiepileptic action is thought to be through decreasing the hyperexcitability of neurons via $\mathrm{Na}^{+}$channel block $\left(\mathrm{IC}_{50}=\right.$ $58 \mu \mathrm{M}$ in serum) (Lang et al., 1993), which it does without causing sedation or interfering with normal central nervous system function (Pincus and Lee, 1973; Yaari et al., 1986; Lang et al., 1993). In lobster axons, phenytoin was shown to decrease sodium influx $\left(\mathrm{IC}_{50} \sim 200 \mu \mathrm{M}\right.$ ) during stimulation but not at rest (Hasbani et al., 1974). Phenytoin also has an inhibitory action on $\mathrm{Ca}^{2+}$ currents in brain slices ( $\mathrm{IC}_{50} \sim 100$ $\mu \mathrm{M})$ (Pincus and Lee, 1973) and PC12 cells $\left(\mathrm{IC}_{50}=9.6 \mu \mathrm{M}\right)$ (Lang et al., 1993). Phenytoin $(0.2 \mathrm{mM})$ reversibly inhibits post-tetanic potentiation, which appears to be through inhibition of presynaptic L-type $\mathrm{Ca}^{2+}$ channels and subsequent neurotransmitter release (Dodge and Rahamimoff, 1967; Delorenzo and Glaser, 1976; DeLorenzo, 1977). In neuroblastoma cells, phenytoin causes voltage-dependent inhibition of T-type $\mathrm{Ca}^{2+}$ currents $\left(\mathrm{IC}_{50} \sim 100 \mu \mathrm{M}\right)$ with no detectable effect on L-type currents (Twombly et al., 1988). The effects of phenytoin on activity of ligand gated intracellular $\mathrm{Ca}^{2+}$ channels such as the RyR are unknown. Here, we investigate the direct effects of phenytoin on RyR2 activity using single-channel recording of RyR2 in artificial lipid bilayers to determine its potential as an inhibitor of diastolic $\mathrm{Ca}^{2+}$ leak. We also investigate phenytoin dependence on calmodulin (CaM), a component of the RyR2 molecular complex (Balshaw et al., 2001), as our previous investigation found that dantrolene inhibition of RyR2 in lipid bilayers and in permeabilized mouse cardiomyocytes required the presence of physiologic concentrations (100 nM) of CaM (Oo et al., 2015).

\section{Materials and Methods}

Heart Tissues and SR Vesicle Isolation. The collection and use of human tissue was approved by the Human Research Ethics Committees of the University of Newcastle (H-2009-0369), The Prince Charles Hospital (Metro North Hospital and Health Service, EC28114), St Vincent's Hospital (H03/118), the Sydney Heart Bank at the University of Sydney (2012-2814), and the University of Canberra (2013/01). Sheep hearts were obtained with approval from the Animal Care and Ethics Committee of the University of Newcastle (approval number A-2009-153). Details of tissue harvesting and SR vesicle isolation are given in Supplemental Table 1 and described previously (Walweel et al., 2017, 2019).

Single-Channel Recording. RyR2 were incorporated into artificial lipid bilayers formed from phosphatidylethanolamine (PE) and phosphatidylcholine (8:2 wt/wt; Avanti Polar Lipids, Alabaster, AL) in n-decane $(50 \mathrm{mg} / \mathrm{ml}$; ICN Biomedicals, Irvine, CA). The lipid mixture was applied across a $100-\mu \mathrm{m}$-diameter hole in a delrin cup separating cis and trans baths. SR vesicles were added to the cis bath, which was stirred until single channel currents indicated the fusion of an SR vesicle with the bilayer. SR vesicles fuse with the bilayer such that the cytoplasmic domain of RyR2 faces the cis bath (Laver et al., 1995). During stirring, the cis (cytoplasmic) bath contained $250 \mathrm{mM} \mathrm{Cs}^{+}$ $\left(230 \mathrm{mM} \mathrm{CsCH} \mathrm{O}_{3} \mathrm{~S}, 20 \mathrm{mM} \mathrm{CsCl}\right.$ ) obtained from Sigma Aldrich (St. Louis, MO) $+1.0 \mathrm{mM} \mathrm{CaCl}$ obtained from BDH Chemicals (VWR, Radnor, PA). The trans (SR luminal) bath contained $50 \mathrm{mM} \mathrm{Cs}^{+}$ $\left(30 \mathrm{mM} \mathrm{CsCH} \mathrm{O}_{3} \mathrm{~S}, 20 \mathrm{mM} \mathrm{CsCl}\right)+$ either $0.1 \mathrm{mM} \mathrm{CaCl}_{2}$ or $1 \mathrm{mM}$ $\mathrm{CaCl}_{2}$. When ion channels were detected in the bilayer, the trans $\left[\mathrm{Cs}^{+}\right]$ was raised to $250 \mathrm{mM}$ by $50 \mu \mathrm{l}$ aliquot addition of $4 \mathrm{M} \mathrm{CsCH}_{3} \mathrm{O}_{3} \mathrm{~S}$. For single-channel recording, the cis solution near the lipid bilayer was replaced by recording solutions flowing from a tube, which was connected via a micromanifold to eight independently controlled syringe pumps. This local perfusion system allowed exposure of RyR2 to multiple serial bathing conditions while simultaneously measuring RyR2 activity (Laver, 2001). All solutions were $\mathrm{pH}$ buffered using $10 \mathrm{mM}$ TES (N-tris [hydroxymethyl] methyl-2 aminoethanesulfonic acid) and titrated to $\mathrm{pH} 7.4$ using $\mathrm{CsOH}$ (ICN Biomedicals). Cytoplasmic recording solutions were buffered to a redox potential of $-232 \mathrm{mV}$ with glutathione disulfide $(0.2 \mathrm{mM})$ and glutathione $(4 \mathrm{mM})$, and luminal solutions were buffered to a redox potential of $-180 \mathrm{mV}$ with glutathione disulfide $(3 \mathrm{mM})$ and glutathione $(2 \mathrm{mM})$, which were both obtained from MP Biomedicals (Irvine, CA). A Ca ${ }^{2+}$ electrode (Radiometer, Brea, CA) was used to determine the purity of $\mathrm{Ca}^{2+}$ buffers and $\mathrm{Ca}^{2+}$ stock solutions as well as free $\left[\mathrm{Ca}^{2+}\right]>100 \mathrm{nM}$. Free $\mathrm{Ca}^{2+}$ was titrated with $\mathrm{CaCl}_{2}$ and buffered using $4.5 \mathrm{mM}$ BAPTA [1,2-bis (o-aminophenoxy) ethane-N,N,N9,N9-tetraacetic acid obtained from Invitrogen (Carlsbad, CA); free $\left.\left[\mathrm{Ca}^{2+}\right]<1 \mu \mathrm{M}\right]$ or dibromo-BAPTA obtained from Molecular Probes (up to $2 \mathrm{mM}$; free $\left[\mathrm{Ca}^{2+}\right]$ between 1 and $10 \mu \mathrm{M}$ ). $\mathrm{MgCl}_{2}$ was obtained from BDH Chemicals (VWR), ATP was obtained from Sigma, and calmodulin was from Sigma Aldrich (prepared from bovine testes) and Enzo Life Sciences (Farmingdale, NY; prepared from pig brain). Dantrolene and phenytoin (powder) were obtained from Sigma Aldrich. They were prepared as stock solutions in dimethylsulfoxide, which was obtained from MP Biomedicals.

Single-channel recordings were made at room temperature $\left(21-23^{\circ} \mathrm{C}\right)$. Electric potentials are expressed using standard physiologic convention (i.e., cytoplasm relative to SR lumen at virtual ground). Axopatch 200B amplifier (Axon Instruments/Molecular Devices, Sunnyvale, CA) was used to control and record bilayer potential and currents. The current signal was low-pass filtered at $1 \mathrm{kHz}$ and digitized at $5 \mathrm{kHz}$. Single-channel parameters, open probability $\left(P_{o}\right)$, and mean open time and mean closed time were measured using a threshold discriminator at $50 \%$ of channel amplitude (Channel3 software; N.W. Laver, nic@niclaver.com). $P_{o}$ of RYRs in multichannel recordings could be measured from the time-averaged current divided by the unitary current and the number of channels. To determine the number of channels in each experiment, the local perfusion system was turned off to produce strong activation of the RyRs by $5 \mathrm{mM} \mathrm{Ca}^{2+}$ in the cis bath. The inhibitory action of phenytoin and dantrolene were measured by the ratio of RyR2 $P_{o}$ during 30-60-second drug exposures to the mean $P_{o}$ of bracketing 30-60-second periods of vehicle solution. RyR2 gating activity is known to show nonstationary, time-dependent modal behavior (Zahradníková and Zahradník, 1995), and results during such nonstationary periods were excluded from the analysis. Our criterion for nonstationarity was a greater than twofold difference in RyR2 $P_{o}$ during bracketing periods of vehicle solutions.

Statistics. Significant differences between groups were tested using a Student's $t$ test or ANOVA. Data are presented as means \pm S.D. or means \pm S.E. as stated in the text. $P<0.05$ was considered significant, and $P<0.01$ was considered highly significant. Hill equation Michaelis-Menten fits to dose-response data pooled from 
several experiments were optimized using least squares criteria with the MATLAB nonlinear fitting function.

\section{Results}

Unless otherwise stated, RyR2 activity was measured in the presence of $100 \mathrm{nM}$ cytoplasmic $\mathrm{Ca}^{2+}$ and $2 \mathrm{mM}$ ATP. The inhibitory action of phenytoin and dantrolene were measured by the ratio of RyR2 $P_{o}$ during 30-60-second drug exposures to the mean $P_{o}$ of bracketing 30-60-second periods of vehicle solution. Our previous study (Oo et al., 2015) showed that dantrolene inhibition required the presence of CaM. However, phenytoin produced a reversible, concentration-dependent inhibition in sheep RyR2, even in the absence of CaM, with maximal inhibition of $\sim 50 \%, \mathrm{IC}_{50}$ in the range of 10-20 $\mu \mathrm{M}$, and Hill coefficients not significantly different to 1 (Fig. 1; Table 1). We found no dependence of fit parameters on either the voltage ( +40 and $40 \mathrm{mV}$, Fig. 1D) or the presence of CaM (Table $1 ; P>0.16$, one-way ANOVA).

The inhibitory effects of dantrolene and phenytoin in the presence of $100 \mathrm{nM}$ CaM are compared in Fig. 1, B, C, E, and F. Both drugs produced reversible partial ( $50 \%)$ inhibition of sheep RyR2 with Hill coefficients not significantly different to 1 , but dantrolene inhibited with an $\mathrm{IC}_{50}$ of $0.14 \pm 0.01 \mu \mathrm{M}$, $\sim 100$-fold higher potency than phenytoin. Both phenytoin and dantrolene inhibition did not depend on voltage.
A

$$
\begin{array}{lcc}
20 & 3 \mathrm{~s} & \begin{array}{c}
\text { Phenytoin } \\
\text {-CaM }
\end{array} \\
0 \mu \mathrm{M} & -40 \mathrm{mV} \\
& & P_{0}=0.13
\end{array}
$$

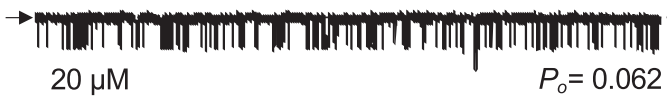
$\rightarrow$ " $0 \mu \mathrm{M}$ $P_{0}=0.09$

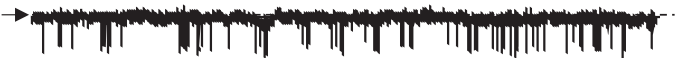 $200 \mu \mathrm{M}$ $P_{0}=0.012$

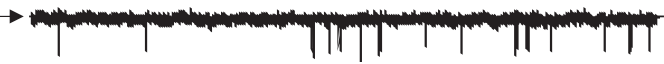

B

Phenytoin
$0 \mu \mathrm{M}$
100 nM CaM
$P_{\mathrm{o}}=0.13$

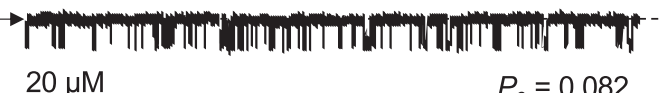

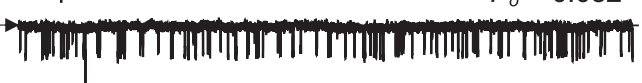
$0 \mu \mathrm{M}$

$P_{0}=0.11$

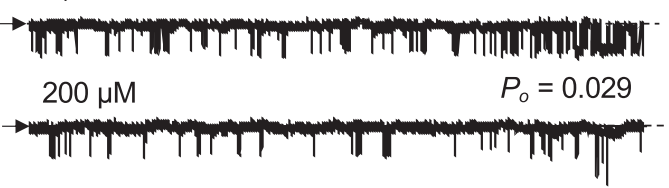

C

\begin{tabular}{|c|c|}
\hline \multicolumn{2}{|c|}{100 nM CaM } \\
\hline $0 \mu \mathrm{M}$ & $P_{o}=0.21$ \\
\hline $0.1 \mu \mathrm{M}$ & $P_{o}=0.11$ \\
\hline & \\
\hline $10 \mu \mathrm{M}$ & $P_{o}=0.04$ \\
\hline
\end{tabular}

Dantrolene

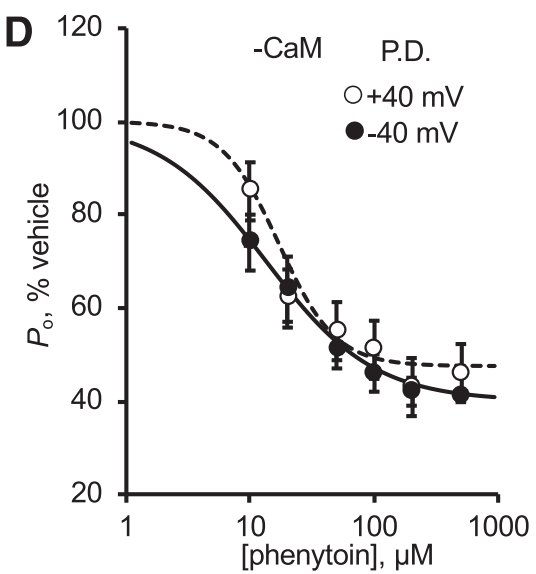

E

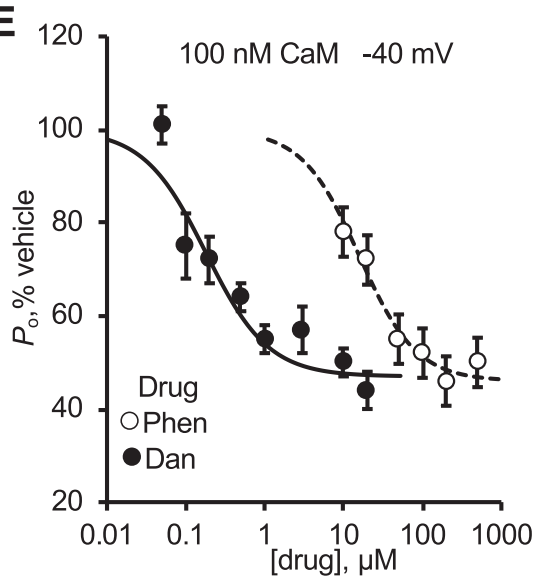

$\mathbf{F}$

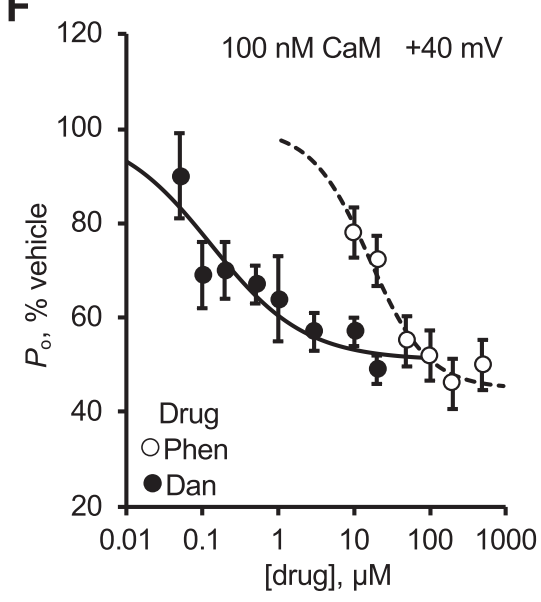

Fig. 1. Phenytoin and dantrolene inhibition of RyR2 from sheep heart. Singlechannel recordings of phenytoin inhibition at $-40 \mathrm{mV}$ in the absence of $\mathrm{CaM}$ (A) and the presence of $\mathrm{CaM}(\mathrm{B})$ and dantrolene inhibition at $-40 \mathrm{mV}$ in the presence of CaM (C). Traces show 30-second segments of RyR2 activity of RyR2 where channel openings are downward currents steps from the baseline (arrows). Drug concentration is given at the left of each trace, and RyR2 open probabilities $\left(P_{o}\right)$ are given at the right. Scale bars in (A) apply to $(\mathrm{A}-\mathrm{C})$. The cytoplasmic bath contains $0.1 \mu \mathrm{M} \mathrm{Ca}^{2+}$ and $2 \mathrm{mM}$ ATP, and the luminal bath contains $0.1 \mathrm{mM}$ $\mathrm{Ca}^{2+}$. (D-F) Averaged data showing dose responses of phenytoin and dantrolene inhibition under conditions listed in (A-C). Error bars are S.E.M. of 13-27 experiments. Solid curves show least-squares fits of the Hill equation to the data compiled from all experiments. An example is shown in Supplemental Fig. 1. The Hill equation and the summary of fit parameters are given in Table 1. 
TABLE 1

Hill equation parameters for drug dose responses

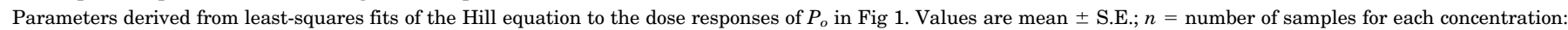
$P_{o}=P_{\max }+\left\{\left(1-P_{\max }\right) /\left(1+\left([\text { Drug }] / I C_{50}\right)^{H}\right)\right\}$.

\begin{tabular}{|c|c|c|c|c|c|c|}
\hline Drug & $\mathrm{CaM} n \mathrm{M}$ & Voltage $\mathrm{mV}$ & $\mathrm{IC}_{50} \mu \mathrm{M}$ & $H$ & $\mathrm{P}_{\max } \%$ & $n$ \\
\hline Phenytoin & 100 & 40 & $16 \pm 4$ & $1.1 \pm 0.4$ & $45 \pm 5$ & $14-19$ \\
\hline Phenytoin & 0 & 40 & $15 \pm 3$ & $1.8 \pm 0.6$ & $46 \pm 3$ & $13-18$ \\
\hline Phenytoin & 100 & -40 & $19 \pm 6$ & $1.0 \pm 0.3$ & $39 \pm 6$ & $13-17$ \\
\hline Phenytoin & 0 & -40 & $13 \pm 3$ & $1.0 \pm 0.7$ & $40 \pm 6$ & $14-27$ \\
\hline Dantrolene & 100 & 40 & $0.13 \pm 0.07$ & $0.6 \pm 0.3$ & $51 \pm 5$ & $13-15$ \\
\hline Dantrolene & 100 & -40 & $0.14 \pm 0.03$ & $1.5 \pm 0.5$ & $53 \pm 3$ & $14-18$ \\
\hline
\end{tabular}

Figure 2 shows a dwell-time analysis of single-channel recordings used for Fig. 1. We investigated phenytoin inhibition under four experimental conditions, including +40 and $-40 \mathrm{mV}$ and the presence and absence of CaM (Fig. 2, A and B), as well as dantrolene inhibition in the presence of CaM (Fig. 2, C and D). Near maximal phenytoin inhibition at $100 \mu \mathrm{M}$ was associated with an approximately twofold increase in the mean closed duration [e.g., mean \pm S.E. $(n): 1.2 \pm$ $0.1 \mathrm{~ms}$ (13) to $2.6 \pm 0.2 \mathrm{~ms}$ (22) at $-40 \mathrm{mV}$ and $1.1 \pm 0.2 \mathrm{~ms}$ (15) to $2.3 \pm 0.3(15)$ at $+40 \mathrm{mV} ; P<0.03,100 \mu \mathrm{M}$ vs. zero, two-way ANOVA] in the absence of CaM. Mean open duration decreased by $\sim 40 \%$ [e.g., $0.9 \pm 0.07 \mathrm{~ms}$ (13) to $0.6 \pm 0.05 \mathrm{~ms}(22)$ at $-40 \mathrm{mV}$ and $0.95 \pm 0.02 \mathrm{~ms}$ (15) to $0.68 \pm 0.03$ (15) at +40 $\mathrm{mV} ; P<0.01,100 \mu \mathrm{M}$ vs. zero, two way ANOVA] in the absence of CaM. There were no significant differences between the four combinations of experimental conditions $(P>0.2$, $100 \mu \mathrm{M}$ vs. zero, presence vs. absence of $\mathrm{CaM}$, and $+40 \mathrm{mV}$ vs. $-40 \mathrm{mV}$, three-way ANOVA). Dantrolene inhibition at a concentration of $10 \mu \mathrm{M}$, where the effect was near maximal, produced an increase in the mean closed time at $+40 \mathrm{mV}$ and $-40 \mathrm{mV}$ in the presence of $\mathrm{CaM}(P<0.01,10 \mu \mathrm{M}$ vs. zero, twoway ANOVA) [e.g., $0.8 \pm 0.1 \mathrm{~ms}(7)$ to $2.2 \pm 0.3 \mathrm{~ms}$ (8) at -40 $\mathrm{mV}$. Mean open time decreased by $\sim 40 \%$ at +40 and $-40 \mathrm{mV}$ in the presence of CaM [e.g., $1.0 \pm 0.07 \mathrm{~ms}$ (7) to $0.6 \pm 0.05 \mathrm{~ms}$ (8) at $-40 \mathrm{mV} ; P<0.01,10 \mu \mathrm{M}$ vs. zero, two-way ANOVA]. As for dantrolene, there were no significant differences between +40 and $-40 \mathrm{mV}$ conditions $(P>0.3,+40 \mathrm{mV}$ vs. $-40 \mathrm{mV}$, two-way ANOVA).

Next, we examined how near-maximal inhibition by phenytoin $(100 \mu \mathrm{M})$ and dantrolene $(10 \mu \mathrm{M})$ depended on ionic conditions (Fig. 3). Inhibition by phenytoin and dantrolene diminished with increasing cytoplasmic $\left[\mathrm{Ca}^{2+}\right]$ from $\sim 50 \%$ at $0.1 \mu \mathrm{M}$ (end-diastolic $\left[\mathrm{Ca}^{2+}\right]$ ) to no significant inhibition at $100 \mu \mathrm{M}$ (systolic $\left[\mathrm{Ca}^{2+}\right.$ ]; Fig. 3A). The diminished effects of phenytoin and dantrolene with increasing cytoplasmic $\left[\mathrm{Ca}^{2+}\right]$ on RyR2 $\mathrm{P}_{\mathrm{o}}$ as well as open and closed dwell-times can be seen in Fig. 3B. Because cytoplasmic $\left[\mathrm{Mg}^{2+}\right]$ is a competitive antagonist that competes with $\mathrm{Ca}^{2+}$ binding and activation of RyR2, we checked to see if phenytoin still failed to inhibit RyR2 at $100 \mu \mathrm{M} \mathrm{Ca}^{2+}$ in the presence of physiologic levels of $\mathrm{Mg}^{2+}(1 \mathrm{mM}$ $\mathrm{Mg}^{2+}$ is produced by $3 \mathrm{mM} \mathrm{MgCl} 2$ in the presence of $2 \mathrm{mM} \mathrm{ATP}$ ). In the presence $\mathrm{Mg}^{2+}$, phenytoin still produced no significant inhibition of RyR2 (0.95 \pm 0.09 , S.D., $n=12$; Fig. 3, B and $\mathrm{C})$. Thus, it appears that phenytoin and dantrolene are both inhibitors at diastolic cytoplasmic $\left[\mathrm{Ca}^{2+}\right]$ but not at systolic $\left[\mathrm{Ca}^{2+}\right]$.

Because RyR2 sensitivity to luminal $\left[\mathrm{Ca}^{2+}\right]$ is a major determinant of diastolic SR Ca ${ }^{2+}$ leak (e.g., Jiang et al., 2005), we checked to see if RyR2 channels responded to phenytoin with luminal $\mathrm{Ca}^{2+}$ close to $1 \mathrm{mM}$ that is achieved during diastole.
Figure 3, B and $\mathrm{C}$ shows that in the presence of end-diastolic cytoplasmic $\left[\mathrm{Ca}^{2+}\right]$, phenytoin had similar inhibitory actions on RyR2 at both 0.1 and $1 \mathrm{mM}$ luminal $\left[\mathrm{Ca}^{2+}\right]$.

If phenytoin and dantrolene share the same binding site on the RyR2 channel, then phenytoin should not be able to inhibit RyR2 in the presence of saturating concentrations of dantrolene. Hence, we investigated the effect of phenytoin $(100 \mu \mathrm{M})$ in the presence of dantrolene $(10 \mu \mathrm{M})$ and did this both in the presence (Fig. 4A) and absence of CaM (Fig. 4B). Grouped data (Fig. 4C) shows that phenytoin inhibition of RyR2 was not alleviated in the presence of saturating concentrations of dantrolene (in the absence of $\mathrm{CaM}, \mathrm{P}_{\mathrm{o}}$ decreased from $0.28 \pm$ 0.05 to $0.08 \pm 0.01 ; P<0.01$, presence vs. absence of phenytoin two-way ANOVA), indicating that phenytoin and dantrolene do not compete for the same binding site.

We investigated the action of phenytoin on RyR2 from human hearts and compared the effects of phenytoin on RyR2 from healthy and failing human [ischemic cardiomyopathy (ICM)] hearts (Fig. 5). Channel recordings show examples in which phenytoin inhibited RyR2 from failing hearts (Fig. 5A) but not from healthy hearts (Fig. 5B). We found phenytoin had a different action on RyR2 from healthy and failing hearts $(P=0.016$; Fig. 5C). Phenytoin had no significant effect on RyR2 from healthy hearts (H1-H4, $P=0.6$, paired $t$ test) but caused a $\sim 50 \%$ reduction in activity of RyR2 from failing hearts (ICM1-5, $P=2 \times 10^{-12}$, paired $t$ test; Fig. 5D).

\section{Discussion}

We show that the hydantoin, phenytoin, produces a dosedependent inhibition of RyR2 channels from sheep and human failing hearts that follows a hyperbolic inhibition curve with maximal inhibition of $\sim 50 \%$. However, phenytoin had no effect on RyR2 from healthy human hearts. Our finding reveals a potential new target for phenytoin and new mechanisms by which phenytoin may modulate cell function and cardiac rhythm. Phenytoin inhibition shares several characteristics in common with that of dantrolene. Both produce, at most, partial ( $\sim 50 \%$ with Hill coefficient of $\sim 1$ ) inhibition of RyR2 by means of reduced mean open time and increased mean closed times (Fig. 3B), although phenytoin inhibits with 100fold lower potency. Both produce inhibition at diastolic cytoplasmic $\left[\mathrm{Ca}^{2+}\right]$ but not at $\mathrm{Ca}^{2+}$ levels that occur in the dyadic cleft during systole. This explains why dantrolene can reduce diastolic $\mathrm{SR} \mathrm{Ca}^{2+}$ leak and increase $\mathrm{SR}^{2+}{ }^{2+}$ content without interfering with subsequent improvement of the $\mathrm{Ca}^{2+}$ transient (Maxwell et al., 2012). If phenytoin inhibition kinetics are fast enough compared with the cardiac cycle, phenytoin could effectively reduce diastolic $\mathrm{SR} \mathrm{Ca}^{2+}$ leak and improve systolic $\mathrm{Ca}^{2+}$ transients like dantrolene. This 
A

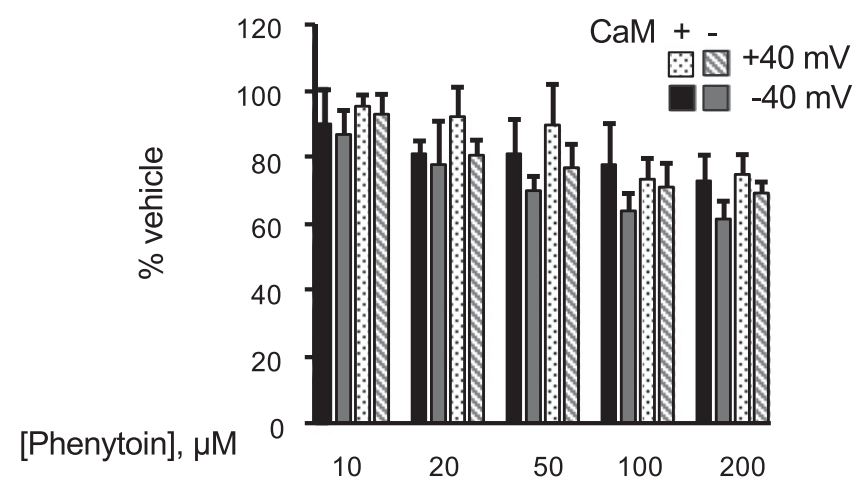

B

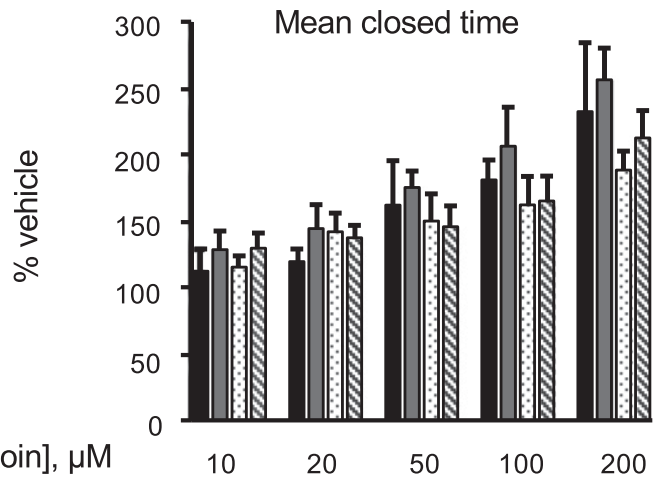

C

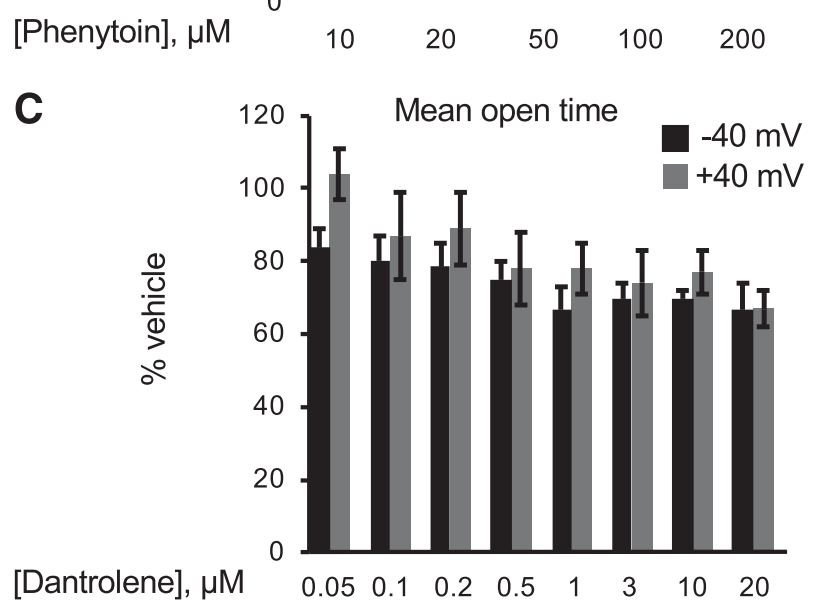

D

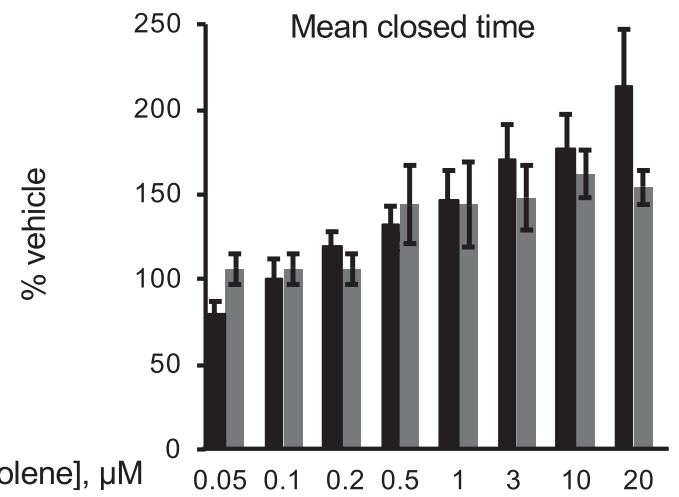

[Dantrolene], $\mu \mathrm{M}$

Mean open time

Fig. 2. Dwell-time analysis on phenytoin (A and B) and dantrolene inhibition (C and D) of sheep RyR2 channels at +40 and $-40 \mathrm{mV}$ in the presence and absence of CaM. The cytoplasmic bath contains $0.1 \mu \mathrm{M}$ $\mathrm{Ca}^{2+}$ and $2 \mathrm{mM}$ ATP, and the luminal bath contains $0.1 \mathrm{mM} \mathrm{Ca}^{2+}$. There was no significant difference in open and closed times between all groups for phenytoin $(P>0.2,100 \mu \mathrm{M}$ vs. zero, presence vs. absence might explain why phenytoin normalized cardiac rhythms in patients who suffered from ventricular arrhythmias and arrhythmias originating from the atria or atrioventricular node (Conn, 1965; Conn et al., 1967; Rosen et al., 1967; Eddy and Singh, 1969).

A surprising finding of this study was that phenytoin inhibited RyR2 from healthy sheep and failing human hearts but not RyR2 from healthy human hearts. We recently reported the same association for CaM inhibition of RyR2, which resulted from the dependence of CaM inhibition on RyR2 phosphorylation at S2808 and S2814 (Walweel et al., 2019). We previously showed that RyR2 from failing hearts had significant hyper-phosphorylation of S2808 and S2814, a reduced free thiol content, and a reduced interaction with FKBP12.0 and FKBP12.6 compared with healthy hearts (Walweel et al., 2017). Interestingly, sheep RyR2s were also significantly hyper-phosphorylated at S2808 compared with healthy human RyR2, possibly because of higher adrenergic stress in sheep compared with humans prior to heart harvest or because of different adrenergic mechanisms for each species (phosphorylation of S2808 and S2814 are increased by adrenergic stress) (Benkusky et al., 2007; Ferrero et al., 2007). In humans, adrenergic stimulation is predominantly through a stimulatory $\mathrm{G}_{\mathrm{s}, \alpha}$-protein cAMP-PKA pathway (Kaumann et al., 1999; Molenaar et al., 2000) as opposed to dual $\mathrm{G}_{\mathrm{s}, \alpha}$-inhibitory $\mathrm{G}_{\mathrm{i}}$-protein pathways in other animals (Zheng et al., 2005). In any case, just how RyR2 phosphorylation, oxidation, or other post-translational modifications affect phenytoin inhibition remains to be determined.

A definitive location of the dantrolene binding site on RyR2 is not known. Labeling of RyR1 peptides has revealed a dantrolene binding site region between aa590 and aa609 on each of the four RyR2 subunits (Paul-Pletzer et al., 2002). Although the corresponding peptide sequence in RyR2 binds dantrolene (aa601-620), dantrolene binding was not detected in the intact RyR2. However, this amino acid sequence is located within $30 \AA$ of the interface of the SPRY splA kinaseryanodine receptor domain domain of RyR2 and FKBP (Wang et al., 2011; Yuchi et al., 2015). Our finding that both dantrolene and phenytoin inhibition have Hill coefficients of $\sim 1$ indicates that their binding to only one of the four putative sites on the RyR2 homotetramer is sufficient for inhibition. The absence of competition between phenytoin and dantrolene inhibition indicates that phenytoin and dantrolene have different binding sites. Separate binding sites are also consistent with a major difference in the actions of phenytoin and dantrolene on RyR2. Namely, phenytoin inhibition is independent of the presence of CaM, whereas dantrolene inhibition is only seen in the presence of CaM.

In spite of different binding sites for phenytoin and dantrolene, our finding that they both inhibit RyR2 from failing hearts and not healthy hearts suggests a common mechanism of action. In RyR2, there is a close proximity (Wang et al., 2007) and interaction between the central domain (residues 2460-2495) and N-terminal domain (residues 590-609) (Yamamoto and Ikemoto, 2002a,b), and disruption (unzipping)

of CaM and $+40 \mathrm{mV}$ vs. $-40 \mathrm{mV}$, three-way ANOVA) and dantrolene $(P>0.3,+40 \mathrm{mV}$ vs. $-40 \mathrm{mV}$, two-way ANOVA). Error bars are S.E.M. of $n$ samples; $n=10-27$ for phenytoin, and $n=5-14$ for dantrolene. 
A

$\begin{array}{lll}20 & 4 \mathrm{~s} & {\left[\mathrm{Ca}^{2+}\right]_{\mathrm{L}}=0.1 \mathrm{mM} ;\left[\mathrm{Ca}^{2+}\right]_{\mathrm{C}}=100 \mu \mathrm{M}} \\ \mathrm{pA} & 0 \mathrm{mM} \mathrm{Mg}^{2+}+40 \mathrm{mV}\end{array}$

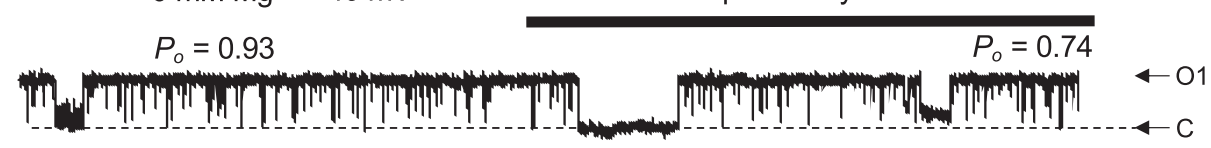

$3 \mathrm{mM} \mathrm{Mg}^{2+}-40 \mathrm{mV}$

$P_{0}=0.26$

$100 \mu \mathrm{M}$ Phenytoin

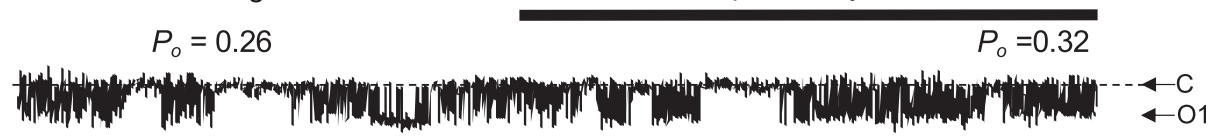

B

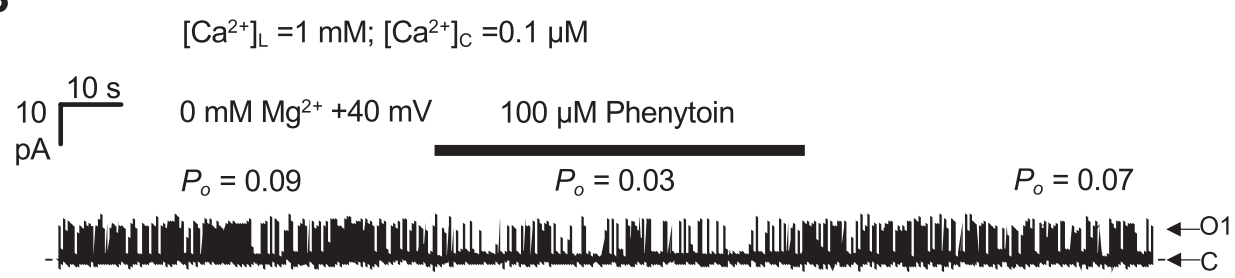

C Open probability Mean open time

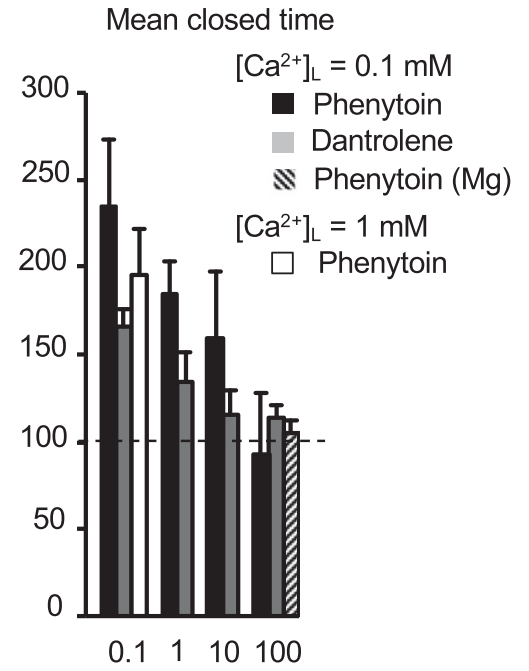

Fig. 3. Phenytoin $(100 \mu \mathrm{M}$, horizontal bars) and dantrolene $(10 \mu \mathrm{M},+100 \mathrm{nM}$ CaM) inhibition of sheep RyR2 under different ionic conditions. The cytoplasmic bath contains $0.1 \mu \mathrm{M} \mathrm{Ca}^{2+}$ and $2 \mathrm{mM}$ ATP, and the luminal bath contains $0.1 \mathrm{mM}$ $\mathrm{Ca}^{2+}$. (A) Representative 60-second traces of a channel in $100 \mu \mathrm{M}$ cytoplasmic $\mathrm{Ca}^{2+}$ plus $2 \mathrm{mM}$ ATP (top trace) and with additional $1 \mathrm{mM} \mathrm{Mg}{ }^{2+}$ (3 $\mathrm{mM} \mathrm{MgCl}{ }_{2}+$ $2 \mathrm{mM}$ ATP, bottom trace). (B) Singlechannel recording of phenytoin inhibition (no CaM) in the presence of $1 \mathrm{mM}$ luminal $\mathrm{Ca}^{2+}$. Trace shows 180 -second segment of RyR2 activity, showing the lack of action of phenytoin (horizontal bar). Labels indicate current baseline (C) and channel openings (O1). Open probabilities $\left(P_{o}\right)$ for each bathing condition are given for each trace. (C) Averaged data showing effect of phenytoin and dantrolene on RyR2 open probability and mean open and closed times over a range of cytoplasmic $\left[\mathrm{Ca}^{2+}\right],\left[\mathrm{Mg}^{2+}\right]$, and in the presence of 0.1 and $1 \mathrm{mM}$ luminal $\mathrm{Ca}^{2+}$. Error bars are S.E.M. of $n$ samples. For phenytoin, $n=27,19,7,6$; for dantrolene, $n=30,10,5,6$ for $\left[\mathrm{Ca}^{2+}\right](\mu \mathrm{M})=0.1,1,10$, 100 , respectively. of these domain interactions causes malregulation of RyR2 associated with cardiac arrhythmias and heart failure (Ikemoto and Yamamoto, 2002). Dantrolene $(1 \mu \mathrm{M})$ has been shown to restore the zipped state of RyR2, normalize RyR2 function, and inhibit diastolic $\mathrm{SR} \mathrm{Ca}^{2+}$ leak in failing heart (Kobayashi et al., 2005, 2009). Within this framework, one can understand why dantrolene and phenytoin can correct the defective interdomain interaction and restore normal RyR2 function (Kobayashi et al., 2009), but they have no effect RyR2 from healthy hearts in which interdomain interactions are already stable. Thus, one could hypothesize that phenytoin, like dantrolene, stabilizes the interdomain interactions and restores the zipped state during diastole in failing hearts.

In order for RyR2 to be a clinically useful target for phenytoin, it would need to be able to readily diffuse across the sarcolemma to reach to the sarcoplasmic reticulum membrane (Milanetti et al., 2016), and it would need to inhibit RyR2 channels with concentrations below those which produce toxic inhibition of other ion channels and transporters. The Caco-2 (human colon adenocarcinoma) cell monolayer is widely used for the determination of drug intestinal permeability and absorption (Patil et al., 2012). This assay reveals phenytoin to be a highly membrane-permeable drug (Pade and Stavchansky, 1998; Milanetti et al., 2016), which should readily access RyR2 channels in muscle. We show that phenytoin inhibits RyR2 with an $\mathrm{IC}_{50} \sim 15 \mu \mathrm{M}$, which is substantially lower than its $\mathrm{IC}_{50}$ for other muscle ion transporters, such as $\mathrm{Na}^{+}$channels $\left[\mathrm{IC}_{50}=58 \mu \mathrm{M}\right.$ (Pincus and Lee, 1973; Yaari et al., 1986; Lang et al., 1993)] and L-type and T-type $\mathrm{Ca}^{+2}$ channels $\left[\mathrm{IC}_{50}\right.$ 100-200 $\mu \mathrm{M}$ (Hasbani et al., 1974; Yatani et al., 1986; Twombly et al., 1988)]. Clinical studies show that therapeutic levels of phenytoin (mean serum concentration of $40-80 \mu \mathrm{M}$, $300 \mathrm{mg}$ daily) produces declines in cognitive functions, including performance, concentration, memory, visuomotor functions, and mental speed (Thompson et al., 1981; Andrewes et al., 1986; Pulliainen and Jokelainen, 1994, 1995). These serum concentrations are threefold higher than $\mathrm{IC}_{50}$ for phenytoin inhibition of RyR2 channels. Thus, even when account is 
A

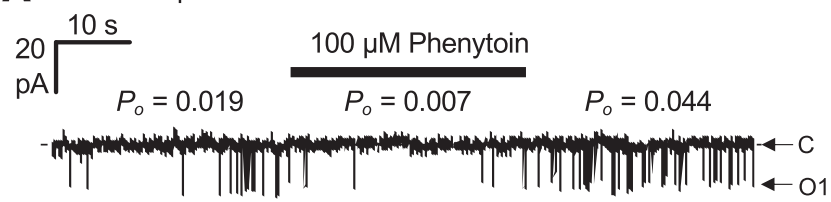

B

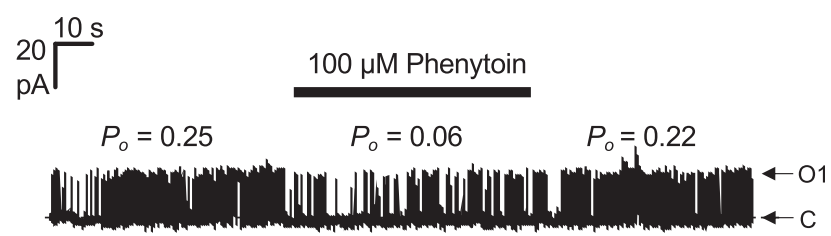

C Phenytoin inhibition

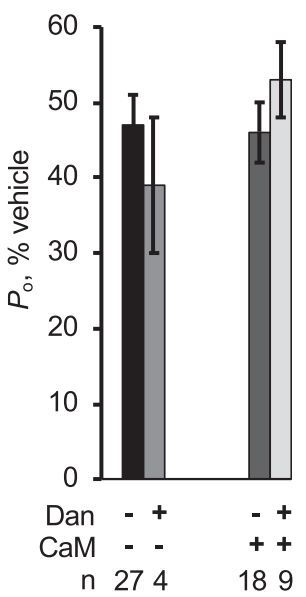

Fig. 4. Single-channel recordings of phenytoin inhibition in the presence of dantrolene in the presence (A) and absence (B) of CaM. Addition of $100 \mu \mathrm{M}$ phenytoin is indicated by the horizontal bars. Labels indicate current baseline (C) and single-channel openings (O1). Open probabilities $\left(P_{o}\right)$ for each experimental condition are given. $(\mathrm{C})$ Averaged data showing the relative phenytoin inhibition under four experimental conditions. The cytoplasmic bath contains $0.1 \mu \mathrm{M} \mathrm{Ca}^{2+}$ and $2 \mathrm{mM}$ ATP, and the luminal bath contains $0.1 \mathrm{mM}$ $\mathrm{Ca}^{2+}$. Error bars are S.D. of $n$ experiments. made for it being a weak acid [pKa 8.06 (Schwartz et al., 1977)], and hence potentially being at a 50\% lower concentration intracellularly, it should still be effective as an inhibitor of RyR2 at therapeutic concentrations typically used as an antiepileptic.

A caveat of this study is that, in our measurements, RyR2 are exposed to phenytoin for $\sim 1$ minute, whereas phenytoin inhibition of $\mathrm{SR} \mathrm{Ca}^{2+}$ leak in humans during therapy may occur over days or weeks. Therefore, we cannot rule out further changes in phenytoin effect with maintained exposure.

In summary, we discovered that phenytoin is an inhibitor of RyR2. It acts as a diastolic inhibitor that would reduce $\mathrm{Ca}^{2+}$ leak from the SR during diastole without adversely inhibiting $\mathrm{SR} \mathrm{Ca}^{2+}$ release during systole. Notably, our experiments with human RyR2 indicate that phenytoin inhibits RyR2 from failing human heart and not from healthy heart, suggesting

A

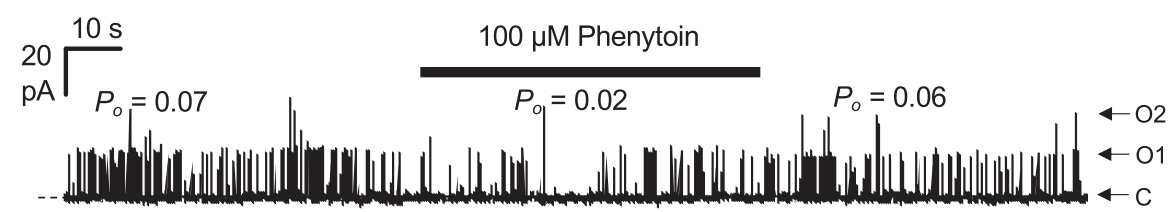

B

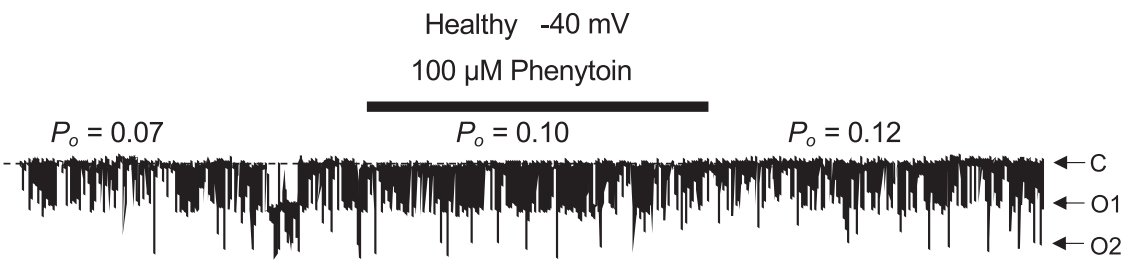

C

Phenytoin inhibition

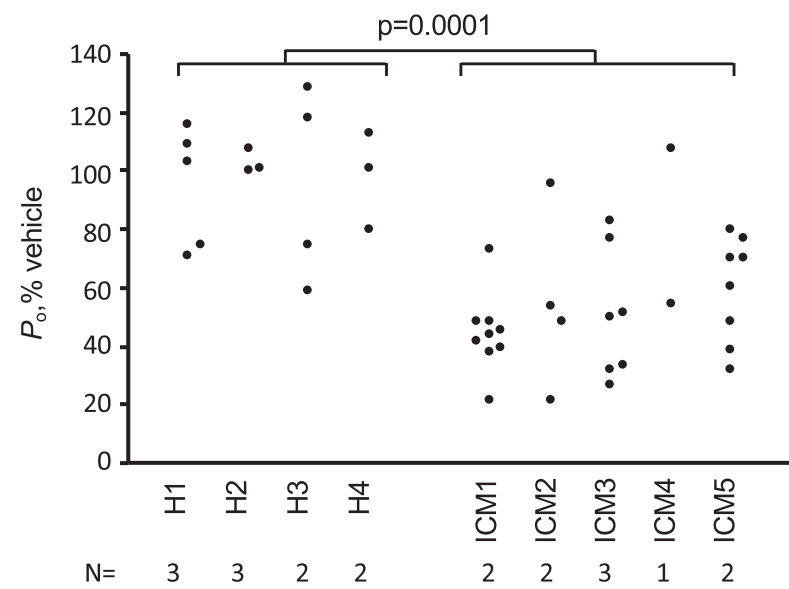

Fig. 5. Representative 180 -second segments of recordings of two channels showing the action of phenytoin on human RyR2 from failing (ICM) hearts (A) and healthy hearts (B). Labels indicate current baseline $(\mathrm{C})$ and openings or one $(\mathrm{O} 1)$ or two (O2) channels. Scale bars in (A) also apply to (B). Open probabilities $\left(P_{o}\right)$ for each bathing condition are given for each trace. (C) Individual measures of relative inhibition by phenytoin from four healthy (H1-H4) and five failing human hearts (ICM1-ICM5). $N=$ number of independent experiments. $P=0.0001$ indicates significant difference between four healthy and five ICM hearts using a two-way ANOVA, with each heart nested in heart health status. (D) Average relative inhibition pooled from all human healthy and failing hearts. Error bars are $95 \%$ confidence limits and $* *$ indicates a highly significant difference from paired vehicle experiments (i.e., 100\%; $P=2 \times 10^{-12}$, paired $t$ test, $n=30$ ). The cytoplasmic bath contains $0.1 \mu \mathrm{M} \mathrm{Ca}^{2+}$ and $2 \mathrm{mM}$ ATP, and the luminal bath contains $0.1 \mathrm{mM} \mathrm{Ca}^{2+}$. 
that phenytoin may selectively target defective RyR2 channels in humans. Moreover, phenytoin inhibition of RyR2 is limited to $50 \%$ at high doses, which permits a wide therapeutic concentration range. Phenytoin has long been chronically used as an antiepileptic through its action of inhibiting voltage-dependent sodium channels. We demonstrate RyR2 inhibition at doses threefold lower than its $\mathrm{IC}_{50}$ for its other known targets in muscle, its therapeutic levels, and levels that produce adverse side effects, pointing to phenytoin as a more human-safe alternative to dantrolene for therapies against heart failure and cardiac arrythmias.

\section{Acknowledgments}

We wish to thank Paul Johnson for assisting with the experiments.

\section{Authorship Contributions}

Participated in research design: Ashna, van Helden, Laver.

Conducted experiments: Ashna.

Contributed new reagents or analytic tools: dos Remedios,

Molenaar, Laver.

Performed data analysis: Ashna, Laver.

Wrote or contributed to the writing of the manuscript: Ashna, van Helden, dos Remedios, Molenaar, Laver.

\section{References}

Andrewes DG, Bullen JG, Tomlinson L, Elwes RD, and Reynolds EH (1986) A comparative study of the cognitive effects of phenytoin and carbamazepine in new referrals with epilepsy. Epilepsia 27:128-134

Balshaw DM, Xu L, Yamaguchi N, Pasek DA, and Meissner G (2001) Calmodulin binding and inhibition of cardiac muscle calcium release channel (ryanodine receptor). J Biol Chem 276:20144-20153.

Benkusky NA, Weber CS, Scherman JA, Farrell EF, Hacker TA, John MC, Powers $\mathrm{PA}$, and Valdivia HH (2007) Intact beta-adrenergic response and unmodified progression toward heart failure in mice with genetic ablation of a major protein kinase A phosphorylation site in the cardiac ryanodine receptor. Circ Res 101 819-829.

Bers DM (2002) Cardiac excitation-contraction coupling. Nature 415:198-205.

Bers DM (2006) Cardiac ryanodine receptor phosphorylation: target sites and functional consequences. Biochem $J$ 396:e1-e3.

Chou CC, Wen MS, Lee HL, Chang PC, Wo HT, Yeh SJ, and Wu D (2014) Dantrolene suppresses ventricular ectopy and arrhythmogenicity with acute myocardial in farction in a langendorff-perfused pacing-induced heart failure rabbit model $J$ Cardiovasc Electrophysiol 25:431-439.

Conn RD (1965) Diphenylhydantoin sodium in cardiac arrhythmias. N Engl J Med 272:277-282.

Conn RD, Kennedy JW, and Blackmon JR (1967) The hemodynamic effects of diphenylhydantoin. Am Heart J 73:500-505.

DeLorenzo RJ (1977) Antagonistic action of diphenylhydantoin and calcium on the level of phosphorylation of particular rat and human brain proteins. Brain Res 134: 125-138.

Delorenzo RJ and Glaser GH (1976) Effect of diphenylhydantoin on the endogenous phosphorylation of brain protein. Brain Res 105:381-386.

Dibb KM, Graham HK, Venetucci LA, Eisner DA, and Trafford AW (2007) Analysis of cellular calcium fluxes in cardiac muscle to understand calcium homeostasis in the heart. Cell Calcium 42:503-512.

Dodge FA Jr. and Rahamimoff R (1967) Co-operative action a calcium ions in transmitter release at the neuromuscular junction. $J$ Physiol 193:419-432.

Eddy JD and Singh SP (1969) Treatment of cardiac arrhythmias with phenytoin. BMJ 4:270-273.

Eisner DA, Caldwell JL, Kistamás K, and Trafford AW (2017) Calcium and excitation-contraction coupling in the heart. Circ Res 121:181-195.

Fabiato A (1983) Calcium-induced release of calcium from the cardiac sarcoplasmic reticulum. Am J Physiol 245:C1-C14.

Ferrero P, Said M, Sánchez G, Vittone L, Valverde C, Donoso P, Mattiazzi A, and Mundiña-Weilenmann C (2007) $\mathrm{Ca} 2+$ /calmodulin kinase II increases ryanodine binding and $\mathrm{Ca} 2+$-induced sarcoplasmic reticulum $\mathrm{Ca} 2+$ release kinetics during beta-adrenergic stimulation. J Mol Cell Cardiol 43:281-291.

George CH, Jundi H, Thomas NL, Fry DL, and Lai FA (2007) Ryanodine receptors and ventricular arrhythmias: emerging trends in mutations, mechanisms and therapies. J Mol Cell Cardiol 42:34-50.

George CH, Jundi H, Walters N, Thomas NL, West RR, and Lai FA (2006) Arrhythmogenic mutation-linked defects in ryanodine receptor autoregulation reveal a novel mechanism of $\mathrm{Ca} 2+$ release channel dysfunction. Circ Res 98:88-97.

Hasbani M, Pincus JH, and Lee SH (1974) Diphenylhydantoin and calcium movement in lobster nerves. Arch Neurol 31:250-254.

Hilliard FA, Steele DS, Laver D, Yang Z, Le Marchand SJ, Chopra N, Piston DW, Huke S, and Knollmann BC (2010) Flecainide inhibits arrhythmogenic Ca2+ waves by open state block of ryanodine receptor $\mathrm{Ca} 2+$ release channels and reduction of $\mathrm{Ca} 2+$ spark mass. J Mol Cell Cardiol 48:293-301.

Hwang HS, Hasdemir C, Laver D, Mehra D, Turhan K, Faggioni M, Yin H, and Knollmann BC (2011) Inhibition of cardiac Ca2+ release channels (RyR2) determines efficacy of class I antiarrhythmic drugs in catecholaminergic polymorphic ventricular tachycardia. Circ Arrhythm Electrophysiol 4:128-135.

Ikemoto $\mathrm{N}$ and Yamamoto $\mathrm{T}$ (2002) Regulation of calcium release by interdomain interaction within ryanodine receptors. Front Biosci 7:d671-d683.

Jiang D, Wang R, Xiao B, Kong H, Hunt DJ, Choi P, Zhang L, and Chen SR (2005) Enhanced store overload-induced $\mathrm{Ca}^{2+}$ release and channel sensitivity to luminal $\mathrm{Ca}^{2+}$ activation are common defects of RyR2 mutations linked to ventricular tachycardia and sudden death. Circ Res 97:1173-1181.

Kaumann A, Bartel S, Molenaar P, Sanders L, Burrell K, Vetter D, Hempel P, Karczewski P, and Krause EG (1999) Activation of beta ${ }_{2}$-adrenergic receptors hastens relaxation and mediates phosphorylation of phospholamban, troponin I, and C-protein in ventricular myocardium from patients with terminal heart failure. Circulation 99:65-72.

Kobayashi S, Bannister ML, Gangopadhyay JP, Hamada T, Parness J, and Ikemoto $\mathrm{N}$ (2005) Dantrolene stabilizes domain interactions within the ryanodine receptor. J Biol Chem 280:6580-6587.

Kobayashi S, Yano M, Suetomi T, Ono M, Tateishi H, Mochizuki M, Xu X, Uchinoumi H, Okuda S, Yamamoto T, et al. (2009) Dantrolene, a therapeutic agent for malignant hyperthermia, markedly improves the function of failing cardiomyocytes by stabilizing interdomain interactions within the ryanodine receptor. $J$ Am Coll Cardiol 53:1993-2005.

Lang DG, Wang CM, and Cooper BR (1993) Lamotrigine, phenytoin and carbamazepine interactions on the sodium current present in N4TG1 mouse neuroblastoma cells. J Pharmacol Exp Ther 266:829-835.

Laver D (2001) The power of single channel recording and analysis: its application to ryanodine receptors in lipid bilayers. Clin Exp Pharmacol Physiol 28:675-686.

Laver DR, Kong CH, Imtiaz MS, and Cannell MB (2013) Termination of calciuminduced calcium release by induction decay: an emergent property of stochastic channel gating and molecular scale architecture. $J$ Mol Cell Cardiol 54:98-100.

Laver DR, Roden LD, Ahern GP, Eager KR, Junankar PR, and Dulhunty AF (1995) Cytoplasmic $\mathrm{Ca} 2+$ inhibits the ryanodine receptor from cardiac muscle. J Membr Biol 147:7-22.

Maxwell JT, Domeier TL, and Blatter LA (2012) Dantrolene prevents arrhythmogenic $\mathrm{Ca} 2+$ release in heart failure. Am J Physiol Heart Circ Physiol 302 H953-H963.

Milanetti E, Raimondo D, and Tramontano A (2016) Prediction of the permeability of neutral drugs inferred from their solvation properties. Bioinformatics 32 $1163-1169$

Molenaar P, Bartel S, Cochrane A, Vetter D, Jalali H, Pohlner P, Burrell K, Karczewski P, Krause EG, and Kaumann A (2000) Both beta $\left({ }_{2}\right)$ - and beta $\left({ }_{1}\right)$-adrenergic receptors mediate hastened relaxation and phosphorylation of phospholamban and troponin I in ventricular myocardium of Fallot infants, consistent with selective coupling of beta $\left(\right.$ )-adrenergic receptors to $\mathrm{G}\left({ }_{\mathrm{s}}\right)$-protein Circulation 102:1814-1821.

Muehlschlegel S and Sims JR (2009) Dantrolene: mechanisms of neuroprotection and possible clinical applications in the neurointensive care unit. Neurocrit Care 10: $103-115$

Oo YW, Gomez-Hurtado N, Walweel K, van Helden DF, Imtiaz MS, Knollmann BC, and Laver DR (2015) Essential role of calmodulin in RyR inhibition by dantrolene. Mol Pharmacol 88:57-63.

Pade V and Stavchansky S (1998) Link between drug absorption solubility and permeability measurements in Caco-2 cells. J Pharm Sci 87:1604-1607.

Patil SR, Kumar L, Kohli G, and Bansal AK (2012) Validated HPLC method for concurrent determination of antipyrine, carbamazepine, furosemide and phenytoin and its application in assessment of drug permeability through caco-2 cell monolayers. Sci Pharm 80:89-100

Paul-Pletzer K, Yamamoto T, Bhat MB, Ma J, Ikemoto N, Jimenez LS, Morimoto H, Williams PG, and Parness J (2002) Identification of a dantrolene-binding sequence on the skeletal muscle ryanodine receptor. J Biol Chem 277:34918-34923.

Pincus JH and Lee S (1973) Diphenylhydantoin and calcium. Relation to norepinephrine release from brain slices. Arch Neurol 29:239-244.

Pölönen RP, Penttinen K, Swan H, and Aalto-Setälä K (2018) Antiarrhythmic effects of carvedilol and flecainide in cardiomyocytes derived from catecholaminergic polymorphic ventricular tachycardia patients. Stem Cells Int 2018:9109503.

Pulliainen V and Jokelainen M (1994) Effects of phenytoin and carbamazepine on cognitive functions in newly diagnosed epileptic patients. Acta Neurol Scand 89: $81-86$

Pulliainen V and Jokelainen M (1995) Comparing the cognitive effects of phenytoin and carbamazepine in long-term monotherapy: a two-year follow-up. Epilepsia 36: 1195-1202.

Rosen M, Lisak R, and Rubin IL (1967) Diphenylhydantoin in cardiac arrhythmias. Am J Cardiol 20:674-678.

Schwartz PA, Rhodes CT, and Cooper JW Jr. (1977) Solubility and ionization characteristics of phenytoin. J Pharm Sci 66:994-997.

Shannon TR, Guo T, and Bers DM (2003) Ca2+ scraps: local depletions of free $[\mathrm{Ca} 2+]$ in cardiac sarcoplasmic reticulum during contractions leave substantial $\mathrm{Ca} 2+\mathrm{re}$ serve. Circ Res 93:40-45.

Thompson P, Huppert FA, and Trimble M (1981) Phenytoin and cognitive function: effects on normal volunteers and implications for epilepsy. $\mathrm{Br} J$ Clin Psychol 20 : 155-162.

Twombly DA, Yoshii M, and Narahashi T (1988) Mechanisms of calcium channel block by phenytoin. J Pharmacol Exp Ther 246:189-195.

Walweel K, Gomez-Hurtado N, Rebbeck RT, Oo YW, Beard NA, Molenaar P, Dos Remedios C, van Helden DF, Cornea RL, Knollmann BC, et al. (2019) Calmodulin inhibition of human RyR2 channels requires phosphorylation of RyR2-S2808 or RyR2-S2814. J Mol Cell Cardiol 130:96-106.

Walweel K, Molenaar P, Imtiaz MS, Denniss A, Dos Remedios C, van Helden DF, Dulhunty AF, Laver DR, and Beard NA (2017) Ryanodine receptor modification and regulation by intracellular $\mathrm{Ca}^{2+}$ and $\mathrm{Mg}^{2+}$ in healthy and failing human hearts. J Mol Cell Cardiol 104:53-62.

Wang R, Chen W, Cai S, Zhang J, Bolstad J, Wagenknecht T, Liu Z, and Chen SR (2007) Localization of an $\mathrm{NH}_{2}$ )-terminal disease-causing mutation hot spot to the 
"clamp" region in the three-dimensional structure of the cardiac ryanodine receptor. J Biol Chem 282:17785-17793.

Wang R, Zhong X, Meng X, Koop A, Tian X, Jones PP, Fruen BR, Wagenknecht T, Liu $\mathrm{Z}$, and Chen SR (2011) Localization of the dantrolene-binding sequence near the FK506-binding protein-binding site in the three-dimensional structure of the ryanodine receptor. J Biol Chem 286:12202-12212.

Yaari Y, Selzer ME, and Pincus JH (1986) Phenytoin: mechanisms of its anticonvulsant action. Ann Neurol 20:171-184.

Yamamoto T and Ikemoto N (2002a) Peptide probe study of the critical regulatory domain of the cardiac ryanodine receptor. Biochem Biophys Res Commun 291: 1102-1108.

Yamamoto T and Ikemoto N (2002b) Spectroscopic monitoring of local conformational changes during the intramolecular domain-domain interaction of the ryanodine receptor. Biochemistry 41:1492-1501.

Yano M, Yamamoto T, Ikemoto N, and Matsuzaki M (2005) Abnormal ryanodine receptor function in heart failure. Pharmacol Ther 107:377-391.

Yatani A, Hamilton SL, and Brown AM (1986) Diphenylhydantoin blocks cardiac calcium channels and binds to the dihydropyridine receptor. Circ Res 59: 356-361.
Yuchi Z, Yuen SM, Lau K, Underhill AQ, Cornea RL, Fessenden JD, and Van Petegem F (2015) Crystal structures of ryanodine receptor SPRY1 and tandemrepeat domains reveal a critical FKBP12 binding determinant. Nat Commun 6 7947

Zahradníková A and Zahradník I (1995) Description of modal gating of the cardiac calcium release channel in planar lipid membranes. Biophys $J$ 69:1780-1788.

Zheng M, Zhu W, Han Q, and Xiao RP (2005) Emerging concepts and therapeutic implications of beta-adrenergic receptor subtype signaling. Pharmacol Ther 108: $257-268$.

Zima AV, Picht E, Bers DM, and Blatter LA (2008) Termination of cardiac $\mathrm{Ca}^{2+}$ sparks: role of intra-SR $\left[\mathrm{Ca}^{2+}\right]$, release flux, and intra-SR $\mathrm{Ca}^{2+}$ diffusion. Circ Res 103:e105-e115.

Address correspondence to: Dr. D.R. Laver, School of Biomedical Sciences and Pharmacy, University of Newcastle and Hunter Medical Research Institute, Callaghan, NSW 2308, Australia. E-mail: Derek.Laver@ newcastle.edu.au 